Ophthalmologe $2017 \cdot 114: 670$

DOI 10.1007/s00347-017-0509-8

Online publiziert: 19. Mai 2017

(c) Springer Medizin Verlag GmbH 2017

CrossMark
T. Ach

Augenklinik und Poliklinik, Universitätsklinikum Würzburg, Würzburg, Deutschland

\section{Leserbrief zu}

Böhm MRR, Thomasen H, Parnitzke F et al (2016) Klinische, morphologische und molekularbiologische Charakteristika des alternden Auges. Ophthalmologe 114:98-107. doi: 10.1007/s00347-016-0403-9

Mit großem Interesse habe ich den Artikel von Böhm und Kollegen [2] gelesen, in dem altersbedingte Veränderungen des Auges den krankheitstypischen gegenübergestellt werden. Diese werden u. a. auch für das retinale Pigmentepithel (RPE) beschrieben. In einer Zwischenüberschrift wird deutlich hervorgehoben, dass die Zelldichte des RPE im Alter abnehme.

Das Phänomen einer RPE-Zelldichteänderung während des normalen Alterns wurde mehrfach in der Literatur beschrieben (eine Zusammenfassung für den interessierten Leser bietet Tabelle S3 in Ach et al. [1]), jedoch offenbaren sich bei genauer Betrachtung der Arbeiten verschiedene Probleme: geringe Probenanzahl, große Spanne der Post-mortemZeiten der Gewebeproben, unterschiedliche Methoden in der Gewebepräparation und Analyse und v. a. die oftmals nicht exakte Definition der retinalen Messorte. Insbesondere letzter Punkt ist essenziell, da sich die RPE-Zelldichte mit zunehmender Entfernung von der Fovea (= Ort höchster RPE-Zelldichte) in Richtung Perifovea und Peripherie deutlich ändert und vermindert [1]. Abweichungen von nur 1-2 mm haben hier merkliche Auswirkungen auf die Zelldichtebestimmung.

Wird die exakte Lokalisation der Fovea in den Analysen berücksichtigt, zeigen die hierzu vorhandenen Studien beinahe ausschließlich eine stabile RPE-Zelldichte im Alter [5, 7]. Dies konnte kürzlich auch an 20 RPE-Spendergeweben bestätigt werden (Fovea; Mittel \pm Standardabweichung): $6520 \pm$ 946 Zellen $/ \mathrm{mm}^{2}$ (10 Spendergewebe $<51$ Jahre) vs. $6405 \pm 1323$ Zellen $/ \mathrm{mm}^{2}$ (10 Spendergewebe $>80$ Jahre), kein signifikanter Unterschied [1]. Im Bereich der Perifovea (601-3000 $\mu \mathrm{m}$ um die Fovea) scheint die RPE-Zelldichte im Alter sogar zuzunehmen $(5091 \pm 823$ vs. $5304 \pm 1005)$, was auf Umbauvorgänge in der einzelligen RPE-Schicht hinweist. Diese Umbauvorgänge können auch elegant an der polygonalen Geometrie der RPE-Zellschicht verdeutlicht werden: Der Anteil hexagonaler Zellen nimmt im Alter ab. Während sich etwa $60 \%$ der RPE-Zellen in der Fovea bzw. $50 \%$ in der Perifovea in jüngeren Jahren ( $<51$ Jahre) hexagonal zeigen, fällt der Anteil dieser im Alter ( $>80$ Jahre) auf etwa $53 \%$ (Fovea) bzw. $46 \%$ (Perifovea) ab [1].

Inwieweit sich für Umbauvorgänge des RPE z.B. regenerative Prozesse, Zellteilung oder auch Fusionen einzelner Zellen verantwortlich zeigen, bleibt in weiteren Arbeiten zu ergründen.

Das RPE scheint jedenfalls gut auf altersbedingte Veränderungen sowohl in der eigenen Zelle (z. B. einer deutlichen Zunahme intrazellulärer Granula wie Lipofuszin und Melanolipofuszin [4]) als auch der unmittelbaren Umgebung (z. B. altersbedingte Fotorezeptordegeneration [3]; Lipideinlagerung und Verdickung der Bruch-Membran [6]) reagieren zu können, um seine Funktionen aufrechtzuerhalten - jedoch, bei geeigneter Methodenwahl, ohne histologischen Nachweis eines Zellverlusts.

\section{Korrespondenzadresse}

\section{Dr. T. Ach, FEBO}

Augenklinik und Poliklinik, Universitätsklinikum Würzburg

Josef-Schneider-Str. 11, 97080 Würzburg,

Deutschland

ach_t@ukw.de

Interessenkonflikt. T. Ach gibt an, dass kein Interessenkonflikt besteht.

\section{Literatur}

1. Ach T, Huisingh C, McGwin G Jr. et al (2014) Quantitative autofluorescence and cell density maps of the human retinal pigment epithelium. Invest Ophthalmol Vis Sci 55:4832-4841

2. Böhm MRR, Thomasen H, Parnitzke F et al (2017) Klinische, morphologische und molekularbiologische Charakteristika des alternden Auges. Ophthalmologe 114:98-107

3. Curcio CA, Millican CL, Allen KA et al (1993) Aging of the human photoreceptor mosaic: evidence for selective vulnerability of rods in central retina. Invest Ophthalmol Vis Sci 34:3278-3296

4. Feeney-Burns L, Hilderbrand ES, Eldridge S (1984) Aging human RPE: morphometric analysis of macular, equatorial, and peripheral cells. Invest Ophthalmol Vis Sci 25:195-200

5. Gao H, Hollyfield JG (1992) Aging of the human retina. Differential loss of neurons and retinal pigment epithelial cells. Invest Ophthalmol Vis Sci 33:1-17

6. Pauleikhoff D, Harper CA, Marshall J et al (1990) Aging changes in Bruch's membrane. A histochemical and morphologic study. Ophthalmology 97:171-178

7. Watzke RC, Soldevilla JD, Trune DR (1993) Morphometric analysis of human retinal pigment epithelium: correlation with age and location. Curr Eye Res 12:133-142 